\title{
Evidence of a 'dinner bell' effect from acoustic transmitters in adult Chinook salmon
}

\author{
A. Michelle Wargo Rub ${ }^{1, *}$, Benjamin P. Sandford ${ }^{2}$ \\ ${ }^{1}$ Fish Ecology Division, Northwest Fisheries Science Center, National Oceanic and Atmospheric Administration, Hammond, \\ Oregon 97121, USA \\ ${ }^{2}$ Fish Ecology Division, Northwest Fisheries Science Center, National Oceanic and Atmospheric Administration, Pasco, \\ Washington 99301, USA
}

\begin{abstract}
The 'dinner bell' hypothesis posits that marine mammals hear or otherwise sense soundwaves produced by acoustic transmitters and use the signal to selectively prey on fish carrying them. A dual tagging study conducted during 2010 and 2011 supports this hypothesis. Results from this study revealed a significant difference in the survival of fish marked with passive integrated transponder (PIT) tags and those marked with active acoustic transmitters. Our objective had been to use both types of tags to study behavior and survival of migrating adult spring Chinook salmon Oncorhynchus tshawytscha at 2 different spatial scales. We tagged fish as they entered the Columbia River, USA, and monitored their survival and progress over a $193 \mathrm{~km}$ reach to Bonneville Dam (river km 234), its lowest impoundment. In 2010, estimated survival was 0.74 (95\% CI, 0.62-0.86) for PIT-tagged fish but only $0.30(0.15-0.45)$ for acoustic-tagged fish. Therefore, in 2011, we included archival tags and a sham acoustic transmitter group to help identify causes of the survival discrepancy. Survival was 0.75 (0.54-0.97) for sham transmitter fish and $0.73(0.60-$ $0.86)$ for PIT fish, but only $0.10(0.00-0.24)$ for active acoustic transmitter fish. Our study area was replete with harbor seals Phoca vitulina, California sea lions Zalophus californianus, and Steller sea lions Eumetopias jubatus during both years. We suspect the most likely cause of survival differences between tag treatment groups was pinniped predation. Using temperature data from archival tags, we found evidence of such predation and support for a 'dinner bell' effect from acoustic transmitter tags.
\end{abstract}

KEY WORDS: Acoustic telemetry · Pinniped hearing · Chinook salmon · Oncorhynchus tshawytscha . Predation · 'Dinner bell'

${ }^{*}$ Corresponding author: michelle.rub@noaa.gov

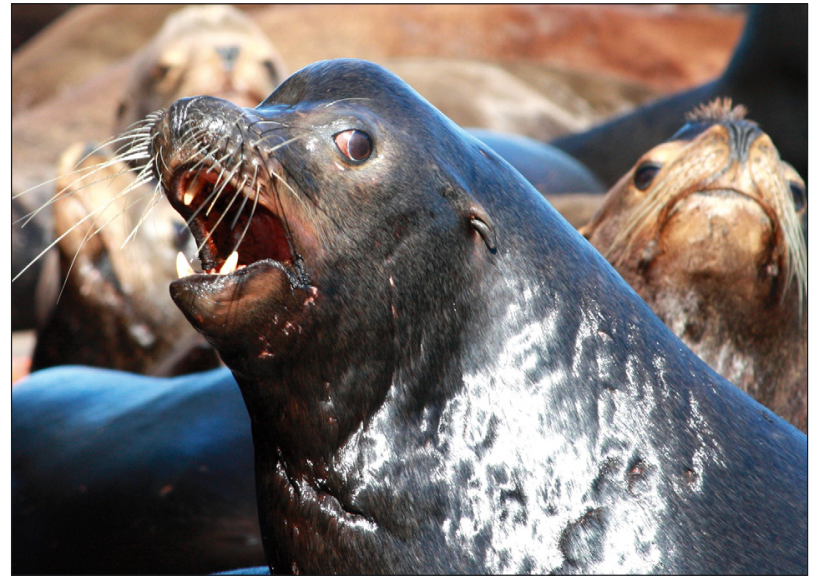

Field-based evidence from the Columbia River, USA, suggests that pinnipeds are capable of using acoustic signals transmitted by tagged fish to assist them in foraging.

Photo: Benjamin P. Sandford

\section{INTRODUCTION}

Ultrasonic acoustic transmitter tags are increasingly used to study behavior and survival in a number of aquatic species world-wide (Donaldson et al. 2014, Hussey et al. 2015). Based on size and morphology of the study animal, these compact electronic devices can be implanted into the body cavity, inserted into the stomach, or attached externally via darts, pins, hooks, clips, sutures, or epoxy (Liedtke \& Wargo Rub 2012, Jepsen et al. 2015). Acoustic transmitters emit a series of short, high-frequency pulses at preprogramed intervals, which are detected and recorded when the tag comes within detection range of a compatible receiver. Transmitters typically pos-

(C) The authors 2020. Open Access under Creative Commons by Attribution Licence. Use, distribution and reproduction are unrestricted. Authors and original publication must be credited. 
sess a unique signature or code so that tagged subjects can be identified individually upon detection. Some transmitters are equipped with sensors to monitor the physical environment, providing archival data on temperature, pressure, conductivity, etc.

Acoustic transmitters are available in a variety of shapes and sizes, with contemporary models weighing as little as $0.2 \mathrm{~g}$ in air (www.atstrack.com). Commercially available transmission frequencies range from 69 to $416.7 \mathrm{kHz}$ and are typically chosen to maximize the distance over which the acoustic signal will travel and thus the reading range of receivers. In aquatic environments, reading range for a given frequency will depend on the medium (i.e. fresh or saltwater).

Tag life can vary from a few days to more than a decade depending on battery size, transmission interval of the signal or ping rate, and output pressure (i.e. the intensity of the signal). Acoustic receivers can be deployed as stationary units throughout a study area, arranged in a strategic array across a thoroughfare, or mobilized using vessels, gliders, or via attachment to other (generally large) animals such as sharks, cetaceans, and pinnipeds (true seals and eared seals), such as described by Hayes et al. (2013).

Based on its many positive attributes, the prospective uses of acoustic telemetry to study aquatic animals within their natural environment are seemingly endless. However, when considering and evaluating uses of this technology, the basic premise of tagging and recapture research must not be overlooked; the tagged animal must remain representative of the untagged population. In other words, neither the transmitter nor the attachment procedure should significantly alter behavior or survival of the tagged animal. In systems where large numbers of marine mammals are known to be present and potentially feeding on the study animal, there may be additional challenges to ensuring the representativeness of tagged subjects.

During a 2 yr study beginning in 2010, we used a combination of passive integrated transponder (PIT) tags and acoustic transmitter (AT) tags to study adult spring Chinook salmon Oncorhynchus tshawytscha behavior and survival through the lower Columbia River, northwestern USA (Fig. 1).
This area was replete with pinnipeds, including harbor seals Phoca vitulina, California sea lions Zalophus californianus, and Steller sea lions Eumetopias jubatus.

First-year results showed differential survival between fish implanted with both AT and PIT tags compared to those implanted with only a PIT tag. We theorized that study fish marked with AT tags were more heavily predated, possibly due to a 'dinner bell' effect, whereby pinnipeds use the acoustic signal to selectively prey on fish carrying ATs. We then modified the study to address the question of whether adult Chinook salmon with active ATs were more vulnerable to pinniped predation than their cohorts implanted with acoustically inert tags.

\section{MATERIALS AND METHODS}

\subsection{Fish sampling and tagging}

During spring 2010 and 2011 we worked with commercial fishermen to sample Chinook salmon adults (defined as measuring at least $560 \mathrm{~mm}$ fork length, FL) as they returned to the estuary to begin their spawning migration. Fish were collected near river $\mathrm{km}(\mathrm{rkm}) 43-44$, as described by Wargo Rub et al.

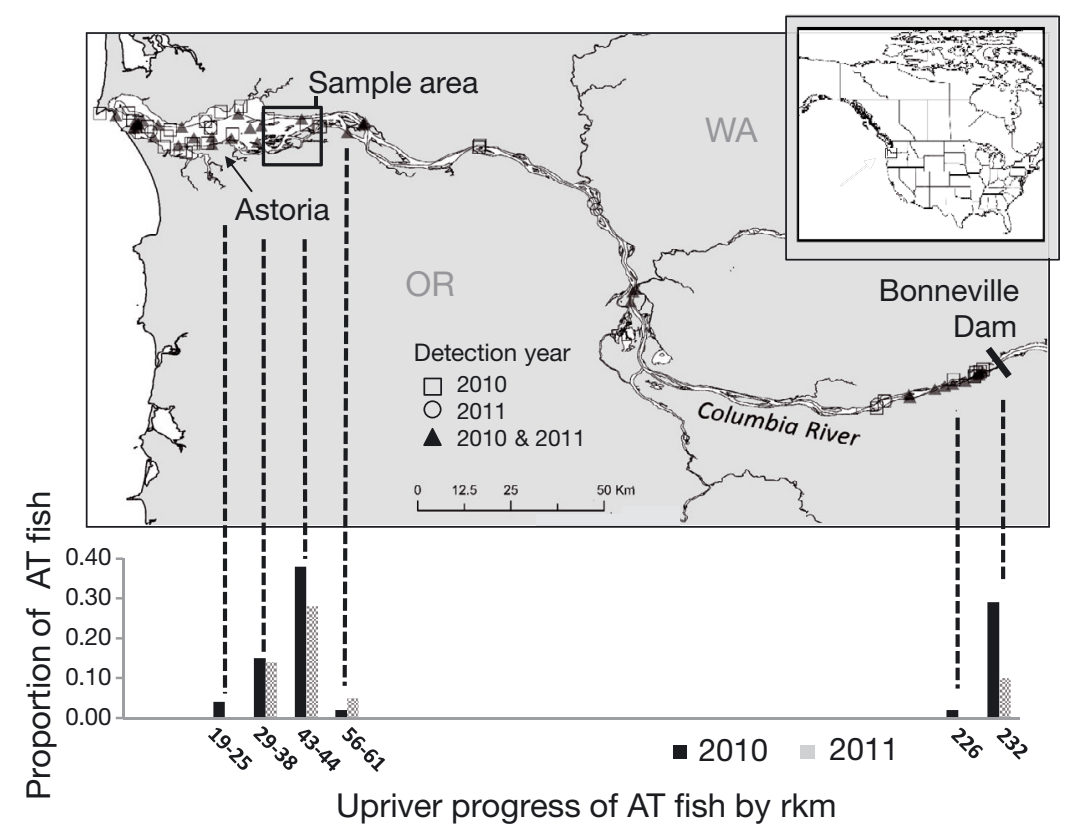

Fig. 1. Columbia River showing Astoria, Oregon (OR), USA, the location of a prominent sea lion haul-out site, our collection and tagging site (river $\mathrm{km}$ [rkm] 43-44), and Bonneville Dam (rkm 234), and the distribution of acoustic telemetry receivers below Bonneville Dam during 2010 and 2011. Chart below shows location (rkm) where acoustic-tagged (AT) adult Chinook salmon were last detected on an acoustic receiver each year. WA: Washington state 
(2012a,b, 2019), using tangle-net fishing gear (4.25 inch $[\sim 10.8 \mathrm{~cm}]$ stretch mesh). Upon landing, fish with no obvious abnormalities on physical examination were placed individually into custom-built, PVC fish tubes. Tubes were held in the river during transport from the sample boat to a tagging vessel. At the tagging vessel, fish were either suspended in the river within their tubes or placed into a holding tank with flow-through river water until they could be processed.

Fish that appeared compromised upon landing (i.e. were lethargic or showed evidence of physical trauma such as an unhealed bite wound) were rejected for treatment. Excluded adults were allowed to recover in a live box supplied with flow-through river water and were released without tagging after recovery. Bycatch species such as steelhead O. mykiss and Chinook salmon jacks (i.e. males that mature and return to freshwater a year earlier than the youngest females) were treated in a similar manner.

Chinook salmon in good condition were physically restrained in dorsal recumbency using a custom aluminum restraint built for this purpose. Treatment fish were measured and scanned for PIT tags, and a pelvic fin clip was obtained for genetic stock identification. Following genetic sampling, non-tagged fish were injected with a PIT tag subcutaneously in the pelvic girdle region. Fish identified as having been PIT-tagged as juveniles were included in the study without subjecting them to additional tagging.

Our main study objective during both years was to estimate survival based on detection of PIT tags at Bonneville Dam. However, we also tagged a subsample of PIT-tagged fish with AT tags to estimate reachlevel survival and to study fish behavior below the dam. For this AT treatment group, we purchased the maximum number of transmitters that our budget allowed. During 2010, survival of the AT group was significantly lower than that of the PIT group. Therefore, during 2011, we established a third tag treatment group to investigate the etiology of this difference. This group was implanted with a PIT tag and a sham (inactive) AT tag.

For both the AT and sham AT groups, 2 tagging methods were used. Transmitters were placed by either gastric insertion into the stomach or by surgical implantation into the peritoneal cavity, using a 1:1 ratio between attachment methods. To assign treatment groups, we used a stratified random sampling approach in an attempt to represent each treatment type equally within each tagging and release group. However, our exclusion criteria based on genetic certainty (see Section 2.3) combined with the variable numbers of fish caught on each sample day, produced an imbalance in treatment group sizes (Table 1, Fig. 2).

Both active and sham acoustic transmitters measured $68 \mathrm{~mm}$ long by $16 \mathrm{~mm}$ in diameter and weighed $24 \mathrm{~g}$ in air, producing an average tag burden well below $1 \%$ (tag mass/fish mass). Active transmitters emitted a signal of $152 \mathrm{~dB}$ re $1 \mu \mathrm{Pa} @ 1 \mathrm{~m}$ at 15 to $45 \mathrm{~s}$ intervals and were programmed for a tag life of $120 \mathrm{~d}$ (VEMCO V16 4L). Active transmitters used in 2011 were equipped with archival temperature sensors. These sensors were used to help discern whether recorded detections had been emitted from a transmitter within a free-swimming fish in the river or within a marine mammal body.

After tagging, all study fish were placed back into their individual fish tubes, where they were allowed to recover in a tank with flow-through river water for a minimum of $20 \mathrm{~min}$. Fish were then released over the side of the vessel to resume migration.

A total of 326 adult Chinook salmon were tagged and released on 14 dates from 14 April through 5 June 2010. Of these fish, 230 were injected with only a PIT tag and 96 were injected with a PIT tag and implanted or inserted with an active AT. During 2011, a total of 629 adult Chinook salmon were tagged and released on 19 dates from 1 April through 16 May. Of these fish, 446 were injected with only a PIT tag, 91 were injected with a PIT tag and implanted or inserted with an active AT tag, and 92 were injected with a PIT tag and implanted or inserted with a sham AT tag.

\subsection{Genetic stock identification}

Fin tissue was collected from each study fish at the time of tagging and later analyzed to identify the most likely origin of each individual, based on genetic stock identification (GSI). Genetic analyses were conducted following the methods of Teel et al. (2009). Fin tissues from tagged fish were genotyped for a set of 13 microsatellite DNA loci that had been standardized among several west coast genetics labs (Seeb et al. 2007). Individual fish were then assigned to 1 of 9 genetic-stock groups identified for the Columbia River Basin (Seeb et al. 2007, Teel et al. 2009).

During 2010, our tagged fish represented the following 4 regional Chinook salmon populations: West Cascade tributary spring, Willamette River spring, Middle and Upper Columbia River spring, and Snake River spring/summer. During 2011, GSI showed that 
Table 1. Number of Chinook salmon by tag treatment used for survival analysis each year. All included fish were genetically identified as originating from stocks upriver from Bonneville Dam with a certainty of at least 0.95. PIT: passive integrated transponder; AT: acoustic transmitter

\begin{tabular}{|c|c|c|c|c|c|}
\hline \multirow[t]{2}{*}{ Date } & \multirow{2}{*}{$\begin{array}{l}\text { PIT tag } \\
\text { only (n) }\end{array}$} & \multicolumn{2}{|c|}{ PIT and AT tag (n) } & \multicolumn{2}{|c|}{ PIT and sham AT tag (n) } \\
\hline & & $\begin{array}{l}\text { Gastric } \\
\text { insertion }\end{array}$ & $\begin{array}{c}\text { Surgical } \\
\text { implantation }\end{array}$ & $\begin{array}{l}\text { Gastric } \\
\text { insertion }\end{array}$ & $\begin{array}{c}\text { Surgical } \\
\text { implantation }\end{array}$ \\
\hline \multicolumn{6}{|l|}{2010} \\
\hline 14 Apr & 19 & 5 & 2 & 0 & 0 \\
\hline $16 \mathrm{Apr}$ & 27 & 3 & 4 & 0 & 0 \\
\hline $20 \mathrm{Apr}$ & 12 & 3 & 4 & 0 & 0 \\
\hline $21 \mathrm{Apr}$ & 4 & 2 & 1 & 0 & 0 \\
\hline 22 Apr & 6 & 2 & 0 & 0 & 0 \\
\hline 23 Apr & 13 & 2 & 2 & 0 & 0 \\
\hline $24 \mathrm{Apr}$ & 11 & 1 & 3 & 0 & 0 \\
\hline $25 \mathrm{Apr}$ & 1 & 1 & 2 & 0 & 0 \\
\hline $28 \mathrm{Apr}$ & 5 & 3 & 1 & 0 & 0 \\
\hline $30 \mathrm{Apr}$ & 13 & 0 & 2 & 0 & 0 \\
\hline 10 May & 1 & 0 & 3 & 0 & 0 \\
\hline 11 May & 3 & 2 & 3 & 0 & 0 \\
\hline 18 May & 0 & 1 & 0 & 0 & 0 \\
\hline Total & 115 & 25 & 27 & 0 & 0 \\
\hline \multicolumn{6}{|l|}{2011} \\
\hline $1 \mathrm{Apr}$ & 18 & 0 & 0 & 0 & 1 \\
\hline $4 \mathrm{Apr}$ & 9 & 2 & 1 & 0 & 1 \\
\hline $5 \mathrm{Apr}$ & 0 & 0 & 1 & 0 & 1 \\
\hline 13 Apr & 9 & 0 & 2 & 2 & 2 \\
\hline $14 \mathrm{Apr}$ & 22 & 1 & 3 & 1 & 2 \\
\hline $18 \mathrm{Apr}$ & 23 & 2 & 3 & 1 & 1 \\
\hline $20 \mathrm{Apr}$ & 19 & 0 & 1 & 3 & 1 \\
\hline $22 \mathrm{Apr}$ & 32 & 1 & 2 & 1 & 0 \\
\hline $27 \mathrm{Apr}$ & 10 & 2 & 1 & 3 & 0 \\
\hline $28 \mathrm{Apr}$ & 6 & 1 & 1 & 1 & 0 \\
\hline $29 \mathrm{Apr}$ & 15 & 1 & 2 & 1 & 1 \\
\hline $30 \mathrm{Apr}$ & 6 & 1 & 1 & 0 & 2 \\
\hline 2 May & 1 & 0 & 1 & 1 & 2 \\
\hline 4 May & 7 & 2 & 2 & 3 & 2 \\
\hline 5 May & 5 & 0 & 2 & 2 & 2 \\
\hline 6 May & 0 & 0 & 1 & 0 & 0 \\
\hline 12 May & 1 & 1 & 1 & 0 & 1 \\
\hline 13 May & 2 & 2 & 0 & 2 & 0 \\
\hline 16 May & 0 & 1 & 0 & 0 & 1 \\
\hline Total & 185 & 17 & 25 & 21 & 20 \\
\hline
\end{tabular}

study fish originated from the same 4 regional populations seen in 2010, as well as from the North Oregon Coast Chinook and Upper Columbia River summer/fall Chinook salmon populations.

\subsection{Estimated survival}

Survival and travel time were estimated only for fish originating from tributaries upstream of Bonneville Dam. Bonneville is the lowermost dam on the Columbia River and thus the first dam encountered by upriver adults migrating to natal streams. Popula- tions crossing Bonneville Dam include those from the Middle and Upper Columbia and Snake Rivers.

We restricted analysis further to include only fish with a probability of at least 0.95 (based on GSI) of having originated upstream from Bonneville Dam. This additional criterion was based on observations that upriver fish tend to stray exclusively into tributaries upstream from Bonneville (Keefer \& Caudill 2014). This exclusion ensured that study fish would not stray into lower river tributaries and thus be mistaken for mortalities in our analyses. Based on this criterion, our final study group in 2010 was reduced from 230 to 115 PIT-tagged fish (including 2 adult fish that had been tagged as juveniles) and from 96 to 52 AT-tagged fish (Table 1). The AT tag group comprised 25 fish with gastrically implanted ATs and 27 fish with surgically implanted ATs. Ten percent of both PIT and AT fish did not have adipose fin clips and were therefore presumed to be of natural origin. Among PIT and AT groups, respectively 58 and $63 \%$ had originated from the Upper and Middle Columbia River and 42 and $37 \%$ had originated from the Snake River. Average fork length was $753 \mathrm{~mm}$ (range $590-880 \mathrm{~mm}$ ) for PIT fish and $769 \mathrm{~mm}$ (range 690$950 \mathrm{~mm}$ ) for AT fish.

During 2011, our final study group was reduced from 446 to 185 PITtagged fish (including 8 adult fish that had been tagged as juveniles); 91 to 42 AT-tagged fish, with 16 gastrically implanted and 26 surgically implanted; and 92 to 41 sham AT-tagged fish, with 21 gastrically implanted and 20 surgically implanted (Table 1). Among the respective PIT, AT, and sham AT groups, 19, 21, and $29 \%$ did not have adipose fin clips and were therefore presumed to be of natural origin. Also among the respective PIT, AT, and sham AT groups, 54, 60, and $66 \%$ of fish had originated from the Upper and Middle Columbia River, while 46, 40, and $34 \%$ had originated from the Snake River.

After adult salmon returns were complete for the year, records of upriver PIT-tagged study fish detected within the Columbia River hydrosystem were 


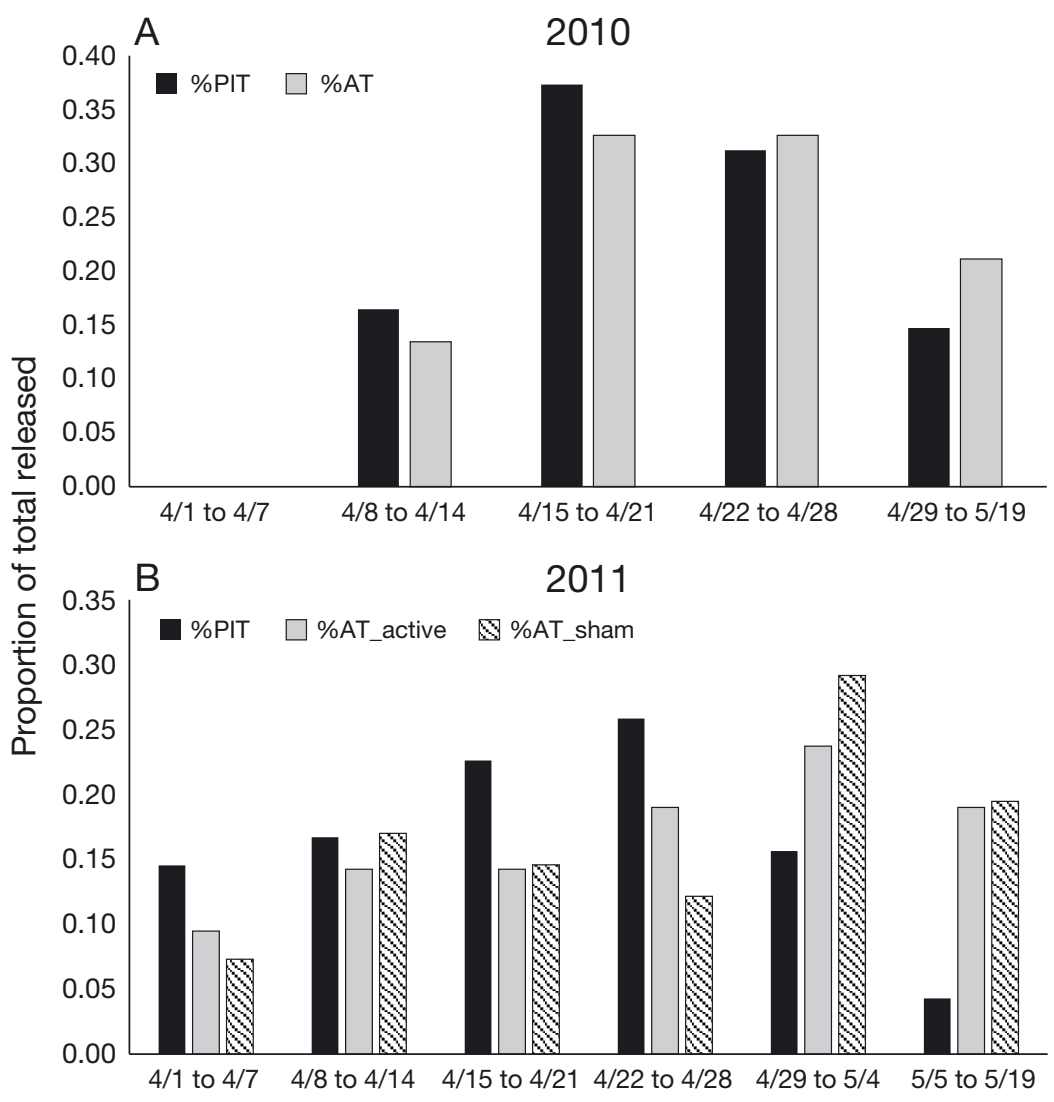

Fig. 2. Percent of each treatment group of adult Chinook salmon tagged during each week of collection (dates given along the $x$-axis) during (A) 2010 and

(B) 2011. PIT: passive integrated transponder; AT: acoustic transmitter html and were determined as follows: First, solve the equation: $\operatorname{BINCDF}\left(N_{w i}\right.$ $\left.S_{w, \mathrm{u}}, R_{W}\right)=\alpha / 2$ for $S_{W, \mathrm{u}}$ to obtain the upper $100(1-\alpha) \%$ limit for $S_{W}$, where BINCDF is the cumulative distribution function of the binomial distribution, $N_{W}=$ the number of successes, and $R_{W}=$ the number of trials. Next solve the equation: $\operatorname{BINCDF}\left(N_{W}-1 ; S_{W, 1}, R_{W}\right)=$ $1-\alpha / 2$ for $S_{W, 1}$ to obtain the lower $100(1-\alpha) \%$ limit for $S_{W}$. Subscript u indicates upper, 1 indicates lower. Note that these intervals are not symmetric about $S_{W}$ (Clopper \& Pearson 1934).

For both 2010 (2 tag treatments) and 2011 (3 tag treatments for 3 tests), we evaluated differences in survival between the weekly cohorts of the tag treatment groups using paired $t$-tests. We assessed the normality assumptions associated with these tests using Shapiro-Wilk tests (Shapiro \& Wilk 1965). Significance was set at $\alpha=0.05$ for 2010 and $\alpha=0.05 / 3=0.017$ (i.e. Bonferroni adjustment to maintain 0.05 overall error rate for multiple tests, Miller 1966) for 2011. These tests were constructed using $\mathrm{R}$ ( $\mathrm{R}$ Core Team 2019).

An annual estimate of survival, $\overline{S_{W}}$, was calculated as the mean of the weekly estimates with standard errors estimated as:

$$
\widehat{\mathrm{SE}\left(\overline{S_{w}}\right)}=\mathrm{SD}\left(\widehat{S_{w}}\right) / \sqrt{W}
$$

where $\operatorname{SD}\left(\widehat{S_{W}}\right)$ was the sample standard deviation of the weekly survival estimates. Intervals for annual means were constructed as:

$$
\left(\overline{S_{w}}-t * \widehat{\mathrm{SE}\left(\overline{S_{W}}\right)}, \overline{S_{w}}+t * \widehat{\mathrm{SE}\left(\overline{S_{w}}\right)}\right)
$$

where $t$ is the 2-tailed $t$-distribution multiplier for annual mean estimates based on degrees of freedom $=W-1$ and $\alpha=0.05$.

For study fish detected at Bonneville Dam, travel time from release was estimated in days. During 2010 and 2011, respectively, movement of AT-tagged fish was also monitored on 70 and 45 individual, stationary acoustic receiver moorings deployed throughout the estuary and lower river from rkm 3 to 233 (Fig. 1). Each receiver mooring included a Vemco VR2W receiver, a mooring buoy, and an anchor. During 2010, all receivers were deployed by the date of the first tagging event with the exception of one that was mial probabilities from https://statpages.info/confint. 
deployed on 30 April at the East Mooring Basin, a marina in Astoria, Oregon, that serves as a conspicuous sea lion haul out site.

During 2011, 18 of 45 receivers were in place prior to the beginning of tagging. The remaining receivers were in place by 7 April, the end of the first tagging week. During 2010 and 2011, respectively, 3 and 7 receivers deployed below Bonneville Dam were lost or were discovered to have drifted offsite during the migration season. Data from these receivers were used through the last record showing the receiver at its deployment location. Remaining receivers were maintained within the lower river throughout summer and into fall.

Based on our 10 yr data set of Chinook salmon passage, this period was well beyond the time frame expected for spring Chinook salmon to migrate through the lower river. Lower river receiver moorings were deployed and maintained by a collaborative group of researchers from the Columbia InterTribal Fish Commission, NOAA, and the US Geological Survey. The frequency of downloading receivers was variable based on location and responsible agency.

Two additional acoustic receiver moorings (of the same composition as those described above) were deployed each year below Lower Granite Dam (rkm 695) in order to evaluate tag loss and detection efficiency of the acoustic receivers at Bonneville. These receivers were maintained by NOAA Fisheries for the duration of the spring Chinook salmon migration at Lower Granite Dam in 2010. However, during 2011, both receivers were lost to extreme high flows in the Snake River before any data could be collected from them.

Acoustic detections were assumed to have been from live fish when (1) commensurate temperatures were within the range of ambient river water $\left(8-10^{\circ} \mathrm{C}\right)$, and $(2)$ detection did not persist over several hours in a stationary location, as would occur if a transmitter had been deposited/ dropped on the river bottom. Detections were assumed to have been from marine mammals if their commensurate temperatures were within the range of mammalian body temperature $\left(36-38^{\circ} \mathrm{C}\right)$.

\section{RESULTS}

\subsection{Survival and travel time}

During 2010, 83 of 115 fish PIT-tagged and released to the estuary were detected at upstream dams. Of these fish, 81 were first detected at Bonneville and 2 were first detected at McNary Dam (rkm 470), the next upstream dam equipped with adult PIT-tag monitoring systems. Mean annual survival to Bonneville for PIT-tagged fish was estimated at 0.74 (95\% CI: 0.62-0.86). Of the 52 fish implanted with AT tags in 2010, 15 were detected upstream after release, and all were detected first at Bonneville Dam. Survival for these fish was estimated at 0.30 (0.15-0.45; Fig. 3), with identical estimates for surgically and gastrically tagged subgroups. The difference in survival of 0.44 between the PIT- and AT-tagged fish was highly significant (paired $t$-test, $\mathrm{p}=0.004$ ). The assumption of data normality was reasonable (Shapiro-Wilk test, $\mathrm{p}=$ 0.564).

Among surviving fish, mean travel time from release to Bonneville Dam was similar between PIT (15.5 d) and AT (15.2 d) treatment groups. Of the 17

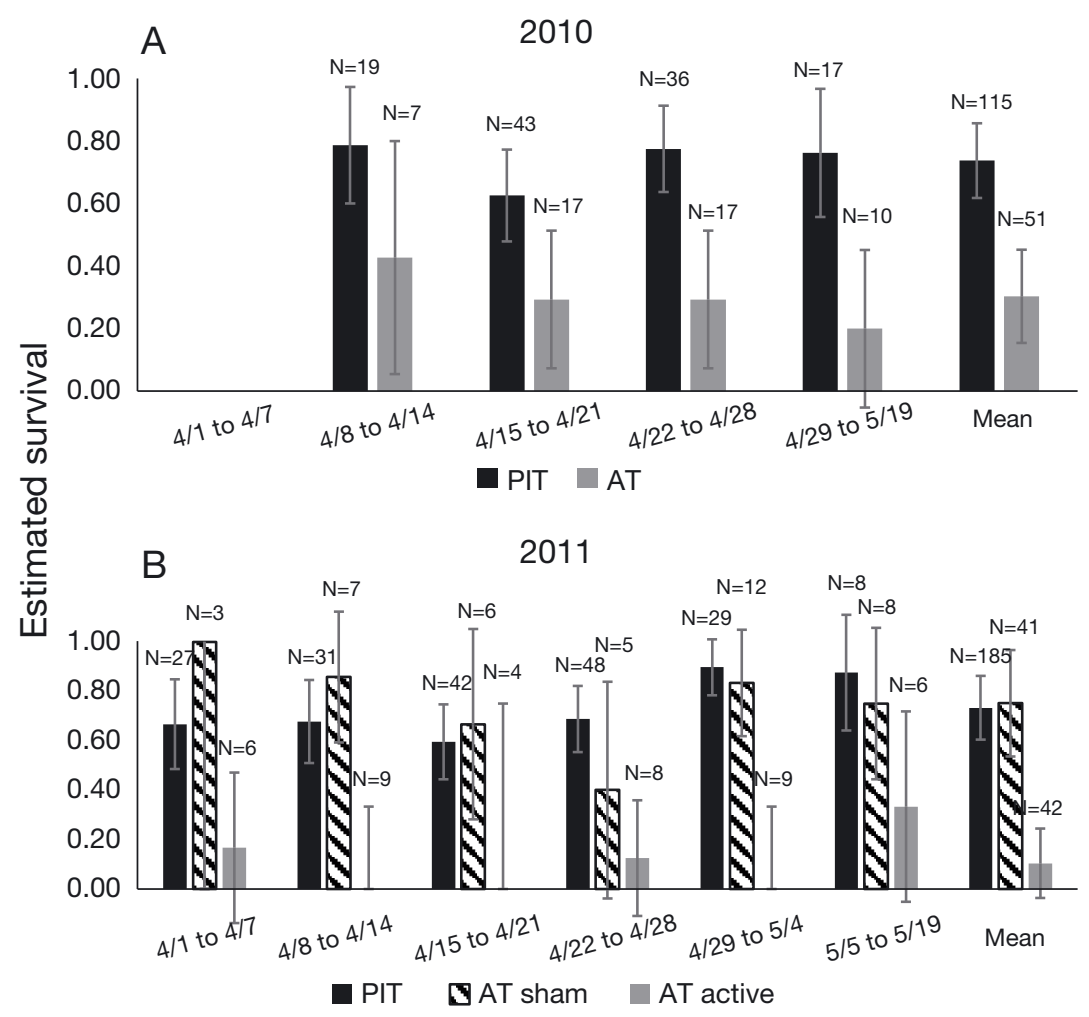

Fig. 3. Percent survival of adult Chinook salmon by treatment (PIT: passive integrated transponder; AT: acoustic transmitter) and week (dates on $x$-axis) tagged during (A) 2010 and (B) 2011. Error bars represent $95 \%$ CIs. N: number of fish in each treatment group 
AT fish detected on acoustic receivers upstream from release, 15 (88\%) survived to Bonneville Dam.

During 2011, 130 of 185 PIT-tagged fish were detected upstream after release, with 128 of these first detected at Bonneville and 2 first detected at McNary. For PIT-tagged fish, mean annual survival to Bonneville Dam was estimated at 0.73 (0.60-0.86). Among the 42 fish with active AT tags, 4 were detected upstream after release, with 4 first detected at Bonneville. Survival for these fish was estimated at $0.10(0.00-0.24)$, with estimates of 0.04 (1 of 26) for surgically tagged and 0.19 (3 of 16) for gastrically tagged fish. Of the 41 fish with sham AT tags, 31 were detected upstream after release, and all 31 were first detected at Bonneville. Survival for sham AT fish was estimated at $0.75(0.54-0.97)$, with estimates of 0.75 for surgically tagged and 0.76 for gastrically tagged fish. The difference in survival of 0.02 between the PIT and sham AT fish was not significant (paired $t$ test, $p=0.850$ ). Estimated survival for both of these tagging groups was much higher than for the active AT group (paired $t$-test, $\mathrm{p} \leq 0.001$ ). Shapiro-Wilk tests indicated the assumption of normality was reasonable (range of p-values was 0.138-0.994).

For surviving fish, mean travel time from release to Bonneville Dam was similar among PIT (21.9 d), active AT $(22.2 \mathrm{~d})$, and sham AT (22.0 d) treatment groups. Of the 6 active AT fish detected on acoustic receivers upstream from release, 4 (67\%) survived to Bonneville Dam.

\subsection{Tag retention rates}

In 2010, all 7 AT fish detected on PIT-tag monitors at Lower Granite Dam were also detected on 1 or more acoustic receivers directly below the dam. These dual detections suggested high AT tag retention for study fish and high detection efficiency of acoustic receivers at Lower Granite. Detections of AT fish in the $15 \mathrm{~km}$ reach below Bonneville Dam were not as high. Of the 15 AT fish known to have passed Bonneville based on PIT-tag detection, only 10 were also detected on acoustic receivers. Of the 7 AT fish detected at Lower Granite Dam, 4 had not been detected as they passed Bonneville. Thus, these missed detections were more likely due to low detection efficiency at the Bonneville location rather than to tag loss. The high rate of missed detections implied that detection efficiency for acoustic receivers at Bonneville Dam could be lower than $50 \%$.

During 2011, acoustic receivers at Lower Granite were lost due to unusually high flows in the Snake
River. Therefore, no information from acoustic receivers at this location was available for evaluations of tag loss or acoustic detection efficiency in the lower river. Of the 4 AT-tagged fish detected at PITtag interrogation sites, 2 were also detected on 1 or more acoustic receivers immediately below Bonneville Dam, between rkm 212 and 234; the other 2 were last detected on acoustic receivers between rkm 140 and 141.

\subsection{Upstream progress of AT-tagged fish}

Of the 52 AT-tagged fish released near rkm 43-44 in 2010, 7 were detected as far upriver as Lower Granite Dam ( 652 km), and 8 others were detected at Bonneville $(\sim 191 \mathrm{~km}$; Fig. 1). One additional acoustic transmitter was last detected just below Bonneville, and another was last detected at rkm 56. Twenty acoustic transmitters were last detected in the vicinity of the release site, while 8 were last detected downstream from the release site, between rkm 29 and 38. Two transmitters were detected even further downstream, between rkm 19 and 25, and 5 were never detected. A total of 5 AT tags were detected some time during spring on the receiver at the East Mooring Basin (a prominent sea lion haulout site).

Among AT study fish that did not pass Bonneville Dam, average time from release to last detection on an acoustic receiver below the dam was $18.8 \mathrm{~d}$ (range $0.5-66 \mathrm{~d}$ ). However, it is important to note that during 2010, we were unable to determine whether acoustic detections below Bonneville Dam were from transmitters within fish or within predators. Fortunately, this was not an issue for fish that passed Bonneville because with few exceptions, the dam serves as an effective barrier to upstream movement of pinnipeds.

Of the 42 fish with active AT tags released during 2011, 4 were detected at Bonneville, 2 were last detected between rkm 59 and 61, and 12 were last detected within the vicinity of release (rkm 43-44). Six transmitters were last detected in fish between rkm 29 and 38, and 14 were never detected.

Four adult Chinook salmon implanted with transmitters in 2011 had tags that were eventually identified within a marine mammal. All 4 of these tags were detected only at or downstream from their release site, whether in fish or mammals. For the 4 transmitters identified within marine mammals, the time between release and the first detection at mammalian body temperature was $1.3,2.2,2.7$, and $42 \mathrm{~d}$ 
(Table 2). Three of these transmitters were detected in fish prior to being detected in a mammal.

Nine transmitters from AT fish that did not meet inclusion criteria for the survival study (i.e. they were either identified as originating from lower CR tributaries or there was a $<0.95$ probability based on GSI that they were from tributaries above Bonneville Dam) were identified within a warm-blooded animal during 2011, meaning ambient temperature based on archival tags was within range of mammalian body temperature $\left(36-38^{\circ} \mathrm{C}\right)$. Among these 9 transmitters, average time between release and first detection within a predator was 2.2 d (range $0.4-$

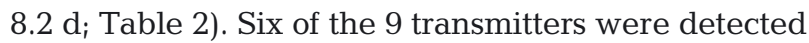
in fish prior to being detected in a warm-blooded animal, and 2 were detected only at the East Mooring Basin haul-out site.

\section{DISCUSSION}

Direct comparison between survival of adult salmon migrants with an AT and a PIT tag vs. those with only a PIT tag provided compelling field-based evidence in support of a 'dinner bell' effect from the AT tag. We concluded that there is a high likelihood that pinnipeds detect signals from ATs in fish and use these signals to assist in foraging.

Information regarding the underwater hearing capabilities of marine mammals at ultra-high frequen-

Table 2. Number of days between release and first detection at marine mammal body temperature $\left(36-38^{\circ} \mathrm{C}\right)$ for acoustic-tagged Chinook salmon during 2011. Also shown are locations where detected tags were presumed to be carried by fish $\left(8-10^{\circ} \mathrm{C}\right)$ vs. marine mammals; rkm: river $\mathrm{km}$

\begin{tabular}{|lccc|}
\hline $\begin{array}{l}\text { Adult } \\
\text { salmon }\end{array}$ & $\begin{array}{c}\text { Time from release } \\
\text { to detection in } \\
\text { marine mammal (d) }\end{array}$ & $\begin{array}{c}\text { Location of } \\
\text { detection in } \\
\text { fish }(\mathrm{rkm})\end{array}$ & $\begin{array}{c}\text { Location of } \\
\text { detection in marine } \\
\text { mammal (rkm) }\end{array}$ \\
\hline Upriver fish & & & \\
1 & 2.7 & $43.6,37.8$ & 43.6 \\
2 & 42 & No detection & 43.6 \\
3 & 1.3 & 43.6 & 43.6 \\
4 & 2.2 & $43.6,37.8,33.0$ & 28.9 \\
Lower river fish and fish with probabilities of upriver origin $<\mathbf{0 . 9 5}$ \\
5 & 0.4 & 43.6 & 28.9 \\
6 & 0.4 & No detection & 37.8 \\
7 & 0.6 & No detection & 43.6 \\
8 & 1.1 & $37.8,33.0$ & 37.8 \\
9 & 8.2 & $33.0,32.2,28.9$, & 28.9 \\
10 & 1.9 & $24.9,18.5,13.7$ & \\
11 & 2.2 & $43.6,37.8,33.0$ & 33.0 \\
12 & 2.6 & $34.4,28.9$ & 20.1 \\
13 & 2.7 & No detection & 37.8 \\
& & 43.6 & 43.6 \\
\hline
\end{tabular}

cies is lacking. However, there is evidence that transmission frequencies of many ATs are well within the hearing range of both harbor seals and sea lions. Bowles et al. (2010a,b) first described aversion by a trained harbor seal to a submerged $69 \mathrm{kHz}$ acoustic tag. Given that $69 \mathrm{kHz}$ is the operational frequency of the commercially available and widely used VEMCO V7-16 AT series, Bowles et al. (2010a,b) concluded that acoustic tags may be 'heard' by some pinnipeds. Experiments by Stansbury et al. (2015) demonstrated the ability of grey seals Halichoerus grypus to locate food using the sound produced by $69 \mathrm{kHz}$ transmitters. These results showed that pinniped exploitation of acoustic signals as a 'dinner bell' is certainly possible.

In another study of captive animals, Cunningham et al. (2014) worked with both a trained harbor seal and a trained California sea lion to recreate pinniped hearing curves at frequencies and intensities similar to those produced by $69 \mathrm{kHz}$ ATs. They demonstrated that both animals were capable of detecting sound at this frequency. Based on earlier studies of pinniped hearing, results from the harbor seal were not surprising (Møhl 1968, Terhune \& Ronald 1972, Kastelein et al. 2009); however, the California sea lion behavior was unexpected (Schusterman et al. 1972, Mulsow et al. 2012).

Cunningham et al. (2014) combined their observed hearing thresholds with sound propagation models for fresh and saltwater to establish theoretical detection ranges of a $69 \mathrm{kHz}$ transmitter for each species. Results indicated that in fresh water, detection ranges for the $69 \mathrm{kHz}$ transmitter signal should extend to over $900 \mathrm{~m}$ for harbor seals and up to $350 \mathrm{~m}$ for California sea lions; in marine waters, respective theoretical ranges were 500 and $200 \mathrm{~m}$. Based on these estimates, both species should be able to detect $69 \mathrm{kHz}$ transmitters at distances well within the range necessary for selective predation.

In our study, data from acoustic receivers indicated that $95 \%$ of fish mortality occurred downstream from the estuary release site (rkm 43-44), where abundance of both seals and sea lions is particularly high. Once fish with active AT tags had progressed upstream past rkm 44, there was a notable increase in survival. The 13 detection tracks obtained from tags confirmed to have been ingested by a marine mammal (from both lower and 
upper river fish combined) indicated that these animals were foraging mostly within the estuary during the spring. None of the marine mammal tracks extended upstream beyond rkm 44. This pattern of foraging was consistent with documentation on harbor seal distribution from the early 1980s (Jeffries et al. 1984). The same pattern was reflected in accounts of sea lion distribution by Wright et al. (2010) and in data from trapping and branding studies by the Oregon Department of Fish and Wildlife (ODFW) during 1997-2017 (ODFW unpubl. data).

Temperature sensor data indicated that for all study fish (upper and lower river origin combined), the average time between release and predation was $2 \mathrm{~d}$ (range $0.4-8 \mathrm{~d}$ with 1 outlier at $42 \mathrm{~d}$ ). This timing indicated that pinniped predation events were not due to an immediate effect of sampling and tagging and were not associated with the presence of our research vessel. Temperature sensor data also established that a portion of AT study fish were consumed by marine mammals. The culprits were sea lions in at least 7 instances, based on temperature data and both stationary and 'warm' detections at a haul-out site exclusive to California and Steller sea lions.

By far, pinnipeds are the most abundant and most frequently documented marine mammals in the lower Columbia River and estuary. Cetaceans, including dolphins and whales, have been observed within the estuary. However, these observations have generally been confined to the lower estuary within a few kilometers of the river mouth and have rarely involved more than 1 or 2 individuals at a time (Jeffries et al. 1984, NOAA Fisheries unpubl. data).

An additional objective for using temperature sensors in 2011 was to evaluate whether the resulting data could be used to accurately measure marine mammal predation. However, the only transmitters detected within marine mammals were from the gastric tag group, indicating a potential bias stemming from attachment method. Considering the similar survival and travel times between treatment groups in both years, higher vulnerability to predation for gastric than surgically tagged fish was unlikely. Another possible explanation for the exclusive observation of gastric tags within pinnipeds included the difference in tag placement within fish. Tags implanted via gastric insertion were seated firmly within the stomach, while surgically implanted tags were placed loosely within the abdominal cavity. As such, surgically implanted tags may have been more likely to shake loose or drop from fish during capture or consumption.
Aside from predation, other potential causes of mortality for returning adult salmon included commercial and sport harvest, delayed effects from collection and tagging, and cumulative effects of disease. Furthermore, fish that strayed into tributaries below Bonneville Dam could not be distinguished from mortalities. However, none of these potential mechanisms are likely responsible for the large survival discrepancy observed between active and passive tagged fish.

During both years, treatment groups were comprised of similar proportions of hatchery and wild fish, based on fin clips, and similar regional population groups, based on GSI. We made every attempt to ensure that tag treatment groups were dispersed across the adult spring Chinook salmon migration season in a representative manner. We also compared survival between treatment groups on a weekly basis. This approach was intended to reduce the effects of environmental differences that may have influenced survival, such as time of day, water clarity, set number, number of pinnipeds present, length of time fish were held, and weather conditions. We also attempted to remove the possibility of mistaking strays for mortalities by excluding fish that originated below Bonneville Dam. These efforts should have effectively excluded most conceivable sources of differential mortality.

We are aware of 1 other field study where fish implanted with ATs were compared directly to those implanted with silent (delayed) ATs (Berejikian et al. 2016). Juvenile steelhead were released to 2 Puget Sound tributaries and tracked by some 80 stationary receivers and 12 mobile acoustic receivers attached to harbor seals. Although harbor seal predation on tagged smolts was verified, no statistical difference was found between tags with active vs. silent signals. Berejikian et al. (2016) suggested several possible explanations for this observation.

First, the length of the study was insufficient for seals to establish a meaningful association between tag signals and prey. Second, the reward for targeting a single juvenile steelhead was not sufficient to influence foraging behavior. Third, Berejikian et al. (2016) suggested that transmission intervals ranging from 30-90 s were too infrequent to aid pinnipeds in capturing these smaller fish. Finally, they suggested that the acoustic environment of Puget Sound was too noisy for seals to distinguish transmitters from background noise. If these fish had been migrating in schools, an additional explanation would be that even if transmitter signals were 'detected', they would have directed predators toward a group of vulnera- 
ble fish (both untagged and tagged) rather than to an individual.

In conclusion, our observations, along with the captive hearing investigations of Bowles et al. (2010b), Cunningham et al. (2014), and Stansbury et al. (2015), have shown that harbor seals and sea lions are capable of both detecting high-frequency soundwaves, such as those emitted by contemporary $69 \mathrm{kHz}$ transmitters, and using them to target potential prey. Given the widespread use of acoustic telemetry in aquatic animal research for estimating survival and the proliferation of commercially available, high-frequency ATs (up to $416.7 \mathrm{kHz}$ ), additional research on the 'dinner bell' hypothesis is warranted. Specifically, clarification is needed regarding the physiological mechanisms by which seals and sea lions detect underwater sound and the limits of these abilities. For example, if pinnipeds are able to detect ATs through non-traditional methods such as bone conductance, as suggested by Repenning (1972), then lowering or increasing the frequency of the soundwave may not eliminate this issue. In the meantime, for studies conducted where marine mammals (including pinnipeds and cetaceans) are present, one should consider alternative methods than acoustic telemetry for estimating survival.

Acknowledgements. We thank Lyle Gilbreath, Lila Charlton, Lynn McComas, Brian, Frank, and Stephanie Tarrabochia, George McCabe, Susan Hinton, and Paul Bentley for their contributions towards data collection. We thank Megan Moore and April Cameron for helping to shape this manuscript and JoAnne Butzerin for helping to pull this manuscript together. This study was funded by NOAA Fisheries. Reference to trade names does not imply endorsement by the National Marine Fisheries Service, NOAA.

\section{LITERATURE CITED}

Berejikian BA, Moore ME, Jeffries SJ (2016) Predator-prey interactions between harbor seals and migrating steelhead trout smolts revealed by acoustic telemetry. Mar Ecol Prog Ser 543:21-35

Bowles AE, Denes SL, Shane M (2010a) Acoustic characteristics of ultrasonic coded transmitters for fishery applications: Could marine mammals hear them? J Acoust Soc Am 128:3223-3231

Bowles AE, Graves SK, Shane M, Denes SL (2010b) Harbor seals respond with aversion to $69-\mathrm{kHz}$ pings: implications for weighting procedures for marine mammal noise metrics. J Acoust Soc Am 127:1803

Burke BJ, Jepson MA, Frick KE, Peery CA (2006) Detection efficiency of a passive integrated transponder (PIT) tag interrogator for adult Chinook salmon at Bonneville Dam, 2005. Report of the National Marine Fisheries Service to the US Army Corps of Engineers, Portland and Walla Walla Districts. NOAA Fisheries, Northwest Fish- eries Science Center, Seattle, WA. www.nwfsc.noaa.gov/ assets/26/1319_07142017_125905_Burke.et.al.2006.pdf

* Clopper CJ, Pearson ES (1934) The use of confidence or fiducial limits illustrated in the case of the binomial. Biometrika 26:404-413

Cunningham KA, Hayes SA, Wargo Rub AM, Reichmuth C (2014) Auditory detection of ultrasonic coded transmitters by seals and sea lions. J Acoust Soc Am 135: 1978-1985

*Donaldson MR, Hinch SG, Suski CD, Fisk AT, Heupel MR, Cooke SJ (2014) Making connections in aquatic ecosystems with acoustic telemetry monitoring. Front Ecol Environ 12:565-573

*Hayes SA, Teutschel NM, Michel CJ, Champagne C and others (2013) Mobile receivers: releasing the mooring to 'see' where fish go. Environ Biol Fishes 96:189-201

*Hussey NE, Kessel ST, Aarestrup K, Cooke SJ and others (2015) Aquatic animal telemetry: a panoramic window into the underwater world. Science 348:1255642

Jeffries S, Treacy, SD, Geiger AC (1984) Marine mammals of the Columbia River estuary. Final report on the marine mammals work unit of the Columbia River Estuary Data Development Program, Washington Department of Game, Olympia, WA. https://www.estuarypartnership.org/sites/ default/files/resource_files/17 \% 20-\%20MARINE \% 20 MAMMALS\%20OF\%20THE\%20COLUMBIA \%20RIVER \%20ESTUARY.pdf (accessed 20 September 2019)

Jepsen N, Thorstad EB, Havn T, Lucas MC (2015) The use of external electronic tags on fish: an evaluation of tag retention and tagging effects. Anim Biotelem 3:49

Kastelein RA, Wensveen PJ, Hoek L, Verboom WC, Terhune JM (2009) Underwater detection of tonal signals between 0.125 and $100 \mathrm{kHz}$ by harbor seals (Phoca vitulina). J Acoust Soc Am 125:1222-1229

*Keefer ML, Caudill CC (2014) Homing and straying by anadromous salmonids: a review of mechanisms and rates. Rev Fish Biol Fish 24:333-368

Liedtke TL, Wargo Rub AM (2012) Techniques for telemetry transmitter attachment and evaluation of transmitter effects on fish performance. In: Adams NS, Beeman JW, Eiler JH (eds) Telemetry techniques: a user guide for fisheries research. American Fisheries Society, Bethesda, MD, p 45-87

Miller RG (1966) Simultaneous statistical inference. SpringerVerlag, New York, NY

Møhl B (1968) Auditory sensitivity of the common seal in air and water. J Aud Res 8:27-38

Mulsow J, Houser DS, Finneran JJ (2012) Underwater psychophysical audiogram of a young male California sea lion (Zalophus californianus). J Acoust Soc Am 131: $4182-4187$

R Core Team (2019) R: a language and environment for statistical computing. R Foundation for Statistical Computing, Vienna. www.R-project.org

Repenning CA (1972) Underwater hearing in seals: functional morphology. In: Harrison RJ (ed) Functional anatomy of marine mammals. Academic Press, London, p 307-331

* Schusterman RJ, Balliet RF, Nixon J (1972) Underwater audiogram of the California sea lion by the conditioned vocalization technique. J Exp Anal Behav 17:339-350

Seeb LW, Antonovich A, Banks MA, Beacham TD and others (2007) Development of a standardized DNA database for Chinook salmon. Fisheries 32:540-552

Shapiro SS, Wilk MB (1965) An analysis of variance test for normality (complete samples). Biometrika 52:591-611 
Stansbury AL, Götz T, Deecke VB, Janik VM (2015) Grey seals use anthropogenic signals from acoustic tags to locate fish: evidence from a simulated foraging task. Proc R Soc B 282:20141595

Teel DJ, Baker C, Kuligowski DR, Friesen TA, Shields B (2009) Genetic stock composition of subyearling Chinook salmon in seasonal floodplain wetlands of the lower Willamette River, Oregon. Trans Am Fish Soc 138: 211-217

Terhune JM, Ronald K (1972) The harp seal, Pagophilus groenlandicus (Erxleben, 1777). III. The underwater audiogram. Can J Zool 50:565-569

Wargo Rub AM, Gilbreath LG, McComas RL, Sandford BP, Teel DJ, Ferguson JW (2012a) Estimated survival of adult spring/summer Chinook salmon from the mouth of the Columbia River to Bonneville Dam, 2010. Report of the National Marine Fisheries Service, Northwest Fish-

Editorial responsibility: Peter Corkeron, Woods Hole, Massachusetts, USA eries Science Center, Seattle, WA. www.nwfsc.noaa.gov/ research/divisions/fe/documents/adult-survival-2010.pdf Wargo Rub AM, Gilbreath LG, McComas RL, Sandford BP, Teel DJ, Ferguson JW (2012b) Survival of adult spring/ summer Chinook salmon from the mouth of the Columbia River to Bonneville Dam, 2011. Report of the National Marine Fisheries Service, Northwest Fisheries Science Center, Seattle, WA. www.nwfsc.noaa.gov/research/ divisions/fe/documents/adult-survival-2011.pdf

Wargo Rub AM, Som NA, Henderson MJ, Sandford BP and others (2019) Changes in adult Chinook salmon (Oncorhynchus tshawytscha) survival within the lower Columbia River amid increasing pinniped abundance. Can J Fish Aquat Sci 76:1862-1873

W Wright BE, Tennis MJ, Brown RF (2010) Movements of male California sea lions captured in the Columbia River. Northwest Sci 84:60-72

Submitted: December 4, 2019; Accepted: April 2, 2020 Proofs received from author(s): May 4, 2020 